\title{
ANÁLISE DESCRITIVA DA ÁREA DE ATUAÇÃO ESPACIAL DO INSTITUTO FEDERAL DE MINAS GERAIS (IFMG)-CAMPUS GOVERNADOR VALADARES: CONTEXTO ATUAL E POSSIBILIDADES
}

\author{
Daniela Martins Cunha ${ }^{1}$ \\ José Antônio Cupertino² \\ Isabela Dias Magalhães ${ }^{3}$ \\ Sylvia Anne Gonçalves Andrade ${ }^{4}$
}

\begin{abstract}
RESUMO
Este trabalho é parte do Projeto de Iniciação Científica desenvolvido no Campus Governador Valadares do IFMG, intitulado como "Mapeamento geográfico e estatístico da área de influência do IFMG-Campus Governador Valadares". Apresenta, de forma descritiva, a área de atuação espacial do campus até o ano de 2012, ou seja, em seus dois primeiros anos de funcionamento. Para isto, utilizou-se como procedimento metodológico a aplicação de questionários aos discentes ativos de todos os cursos do campus, aos transeuntes das ruas centrais e do Terminal Rodoviário, bem como aos discentes de escolas públicas do município. Os dados obtidos nesta pesquisa podem ser utilizados pelos gestores do campus como ferramenta estratégica nas tomadas de decisão, tais como: locais de origem dos discentes, de que forma estes e os demais pesquisados tomaram conhecimento do campus e quais os cursos técnicos e superiores que gostariam que fossem ofertados futuramente. Dentre os principais resultados, destaca-se a necessidade de um maior investimento em trabalhos de divulgação do IFMG-Governador Valadares pelos meios mais populares de marketing, como TV, rádio e jornais, concomitantemente com a divulgação institucional via Comissão Local de Processo Seletivo nas escolas, tendo em vista que os discentes que ingressaram no curso até o segundo semestre de 2012, de acordo com a população pesquisada nas ruas e na rodoviária, tomaram conhecimento do Instituto e de seus cursos principalmente por meio de amigos, ou seja, uma divulgação informal, e não institucional.
\end{abstract}

Palavras-chave: Perfil socioeconômico. Discente IFMG-Governador Valadares. Marketing institucional. Oferta de cursos.

\section{DESCRIPTIVE ANALYSIS OF SPACE AREA OF OPERATION OF THE INSTITUTO FEDERAL DE MINAS GERAIS-CAMPUS GOVERNADOR VALADARES: CURRENT CONTEXT AND POSSIBILITIES}

\footnotetext{
${ }^{1}$ Mestre em Extensão Rural, Especialista em Estudos Ambientais e Graduada em Geografia. Professora e Coordenadora do Curso de Tecnologia em Gestão Ambiental do IFMG-Campus Governador Valadares. E-mail: daniela.cunha@ifmg.edu.br

${ }^{2}$ Graduando do curso de Tecnologia em Gestão Ambiental do IFMG-Campus Governador Valadares. E-mail: josecupertino@ymail.com

${ }^{3}$ Discente do curso Técnico em Segurança do Trabalho do IFMG-Campus Governador Valadares. E-mail: legallybela@hotmail.com

4 Discente do curso Técnico em Segurança do Trabalho do IFMG-Campus Governador Valadares. E-mail: anne.sylvia@hotmail.com
} 


\begin{abstract}
The work is part of the Project of Scientific Initiation developed in the IFMG's campus in Governador Valadares, the work was titled: "Geographical and Statistical Mapping of the area influenced by the IFMG's campus in Governador Valadares". The article presents in a descriptive way the space actuation area of the campus until the year of 2012, in other words, in its first two years of operation. For this, questionnaires were used as methodological instruments and were applied for: students that were frequent in all courses of the campus, people downtown and at bus stations, students from public schools of the city. Then the results of the research that can be used by the managers of the campus as a strategic way for them to make decisions are presented, results such as: origin place of the students, how these and the other researched people knew about the campus and what technical courses and higher they would like offered in the future. Among the conclusions that can be reached with this work some stands out like: It's necessary a higher investment and establishment of a publicity work of the IFMG-Governador Valadares through the more popular means of marketing such as $\mathrm{TV}$, radio and newspaper concomitantly with the institutional divulgation through selective process by the local vestibular commission in schools, in order that the students that entered the course until 2012 such as the people that was researched at the streets and bus stations, will take notice about the institute and its courses mainly by friends, in other words, an informal and non-institutional divulgation.
\end{abstract}

Keywords: Socioeconomic profile. Student IFMG-Governador Valadares. Institutional marketing. Course offerings.

\title{
1 INTRODUÇÃO
}

Com o governo Lula, a educação superior passou por uma reforma iniciada a partir do Decreto de 20 de outubro de 2003, "que instituiu o Grupo de Trabalho Interministerial (GTI), encarregado de analisar a situação da educação superior brasileira e apresentar um plano de ação visando à reestruturação, desenvolvimento e democratização das Instituições Federais de Ensino Superior (IFES)” (OTRANTO, 2012, p. 1). Dentre as várias reformas propostas pelo GTI, que visam, dentre outras metas, à concepção de uma política de democratização do acesso ao ensino superior, ressaltam-se a criação da educação profissional e a elevação dos Centros Federais de Educação Tecnológica à categoria de Instituições Federais de Ensino Superior. Paralelamente a esta ação, tem-se dado continuidade, no Governo Dilma Roussef, a uma política de criação de novos Institutos Federais.

Neste cenário de expansão da educação técnica e tecnológica, foi criado pela Lei 11.892, de 29 de dezembro de 2008, mediante integração dos Centros Federais de Educação Tecnológica de Ouro Preto e de Bambuí e da Escola Agrotécnica de São João Evangelista, o Instituto Federal de Educação, Ciência e Tecnologia de Minas Gerais (IFMG), cuja Reitoria foi instalada em Belo Horizonte. Ainda pelo plano de expansão da educação profissional, 
foram criados outros campi nos municípios de Congonhas, Formiga, Governador Valadares, Ouro Branco, Betim e Ribeirão das Neves, além das Unidades Conveniadas em João Monlevade, Pompéu, Piumhi, Oliveira e Sabará (IFMG, 2012). O campus Governador Valadares foi recentemente criado pelo Instituto Federal com o intuito de atender a uma demanda regional do Médio Rio Doce. Teve sua primeira aula magna inaugural no dia 27 de abril de 2010, para o Curso Superior de Tecnologia em Gestão Ambiental. Atualmente, conta com dois cursos superiores, dois cursos técnicos integrados e um curso técnico subsequente.

A microrregião de Governador Valadares, pertencente à mesorregião do Vale do Rio Doce, compreende um número de 25 municípios, com uma população total de cerca de 415 mil habitantes. É uma região que possui como principais atividades econômicas aquelas ligadas ao setor agrícola e de serviços, com um Produto Interno Bruto (PIB) relativamente baixo, cujas médias ficam em torno de 0,7 (IBGE, 2010). Tal cenário econômico explica a dinâmica populacional regional conhecida nacionalmente pelas migrações ao exterior, principalmente para os Estados Unidos.

Pelos dados socioeconômicos citados, nota-se a importância do estabelecimento de uma instituição federal de ensino na região, principalmente por ter como foco a educação técnica e tecnológica, pois parte-se da premissa de que o instituto gerará conhecimento para atender às necessidades e demandas locais e regionais, principalmente no que diz respeito à preparação de mão de obra qualificada e posterior melhoria da qualidade de vida dessa população.

Da mesma forma:

[...] o acesso e a permanência no ensino superior representam possibilidades de melhores postos no mercado de trabalho e de ascensão social. Além disto, uma formação superior sólida, voltada para a cidadania participativa, é instrumento fundamental para a formação de massa crítica qualificada, indispensável para o alcance de desenvolvimento humano sustentável, com equidade e justiça social (PAULA, 2009, p. 69).

Por outro lado, destaca-se que existem atualmente oito instituições de ensino superior no município de Governador Valadares, sendo cinco de caráter privado e três públicas, o que gera um total de cerca de 65 cursos superiores nas diversas áreas de ensino. Alguns cursos, como o de Engenharia de Produção, são ofertados em três instituições ao mesmo tempo, dentre elas o IFMG. Além disso, existem diversas escolas técnicas que oferecem cursos que também são ofertados pelo campus Governador Valadares.

Dessa forma, por ser relativamente grande a oferta de cursos e instituições no município, mesmo sendo uma instituição de ensino pública, é necessário ao IFMG-Campus 
Governador Valadares o investimento em marketing. Sabe-se que uma das funções do marketing é "estabelecer e manter a ligação entre a organização e seus clientes, consumidores, usuários ou público-alvo. Tanto as organizações lucrativas quanto as não lucrativas realizam atividades de marketing" (MAXIMIANO, 2010, p. 08).

“O bom marketing não é acidental. Ele resulta de planejamento e execução cuidadosos. Em quase todos os setores, as práticas de marketing estão sendo continuamente refinadas e reformuladas para aumentar as chances de sucesso" (KOTLER; KELLER, 2006, p. 02). Para um bom planejamento, é necessário coletar dados sobre os quais serão pautadas e executadas estratégias de lançamento do produto e convencimento de seu uso por novos clientes. Por conseguinte, a melhor ferramenta a ser utilizada para a obtenção de dados é a pesquisa, que, segundo Maximiano (2010), também é uma função do marketing, um mecanismo utilizado para identificar interesses, necessidades e tendências do mercado.

Pela caracterização socioeconômica e educacional da região onde o campus foi instalado, observa-se a necessidade de uma política contínua de expansão para prosseguir o atendimento da demanda regional. E tal política perpassa, dentre outros aspectos, pela necessidade de conhecer e identificar as potencialidades e estratégias mais adequadas de inserção da instituição em um cenário de oferta de cursos superiores e técnicos já estabelecidos no município. Ou seja, identificar as áreas com futuro potencial de atuação do campus, seja por meio de cursos técnicos, superiores ou de capacitação, sendo que estes últimos são e/ou podem ser pensados a partir dos primeiros. Consequentemente, também é necessário identificar de onde vêm os atuais discentes do Instituto, ou seja, de quais bairros do município de Governador Valadares e de quais municípios da região eles se deslocam, a fim de se estabelecer estratégias de marketing.

Assim, este artigo tem como objetivo principal analisar, de forma descritiva, a área de atuação espacial do IFMG-Campus Governador Valadares, bem como identificar potencialidades de atuação futura através da oferta de novos cursos e do marketing mais apropriado. Enfim, deseja-se oferecer dados que poderão ser utilizados como ferramenta estratégica pelos gestores do Campus Governador Valadares, que os orientarão em futuras decisões sobre quais cursos atenderão melhor à demanda social do município e da região; em quais bairros do município, cidades da região e escolas é necessário investir em marketing, com o objetivo de que o Instituto e os serviços por ele oferecidos sejam conhecidos e atendam às reais necessidades da comunidade regional. 


\subsection{Procedimentos Metodológicos}

A pesquisa seguiu as seguintes etapas metodológicas, instrumentalizadas conforme (LAKATOS; MARCONI, 2003; OLIVEIRA, 2005; CRESPO, 2009), a saber: 1- revisão bibliográfica; 2- aplicação de questionários aos discentes de 2012; 3- trabalho de campo e aplicação de questionários; 4- tratamento estatístico dos dados; e 5- elaboração de relatório final com apresentação e análise dos dados.

$1^{\text {o }}$ - Revisão Bibliográfica: constou de uma pesquisa sobre o assunto em livros, artigos e revistas especializadas.

$2^{\circ}$ - Aplicação de questionários aos discentes de 2012: foram aplicados questionários semiestruturados, em dias aleatórios, a todos os discentes de todos os cursos do campus que estivessem em sala de aula, com o objetivo de obter informações sobre o local de origem dos mesmos; de quais bairros de Governador Valadares ou de quais municípios eles se deslocam; quais outros cursos técnicos ou superiores gostariam que fossem ofertados futuramente; e por qual meio de comunicação tomaram conhecimento do campus.

$3^{\text {o- }}$ Trabalho de campo e aplicação de questionários para obtenção de dados nas ruas centrais, que foram escolhidas pelo fluxo de pessoas. Os integrantes da equipe de pesquisa, identificados com uniformes do IFMG-Campus Governador Valadares, convidavam as pessoas que passavam pela Rua Israel Pinheiro, Rua Sete de Setembro e Avenida Minas Gerais para que respondessem o questionário. Para diversificar a opinião, buscou-se questionar de forma igualitária cidadãos de ambos os sexos, sendo que 115 pessoas eram do sexo feminino e 85 do sexo masculino, na faixa etária de 14 a 25 anos, média prevista para ingresso em algum curso do IFMG-GV. Destinou-se um mês para a aplicação dos duzentos questionários contendo questões que visavam verificar se os moradores/pessoas que circulavam pelas ruas conheciam o IFMG-GV e se os mesmos tinham interesse em realizar algum curso no Instituto e, caso a resposta fosse afirmativa, qual seria.

O mesmo questionário foi aplicado a 103 pessoas que circulavam pela Rodoviária de Governador Valadares em horários que estavam correlacionados a viagens inter-regionais, com o objetivo de verificar se os moradores dos municípios vizinhos conheciam o IFMG-GV e se estes se interessariam em realizar algum curso no mesmo, e, caso respondessem afirmativamente, qual seria. Como nas ruas, destinou-se um mês para a realização da pesquisa, buscando questionar, de forma igualitária, pessoas do sexo feminino e do sexo 
masculino. Participaram 57 mulheres e 46 homens, na faixa etária de 14 a 25 anos, a prevista para ingresso em algum curso do IFMG-GV.

Por fim, o questionário também foi aplicado a 351 alunos do $9^{\circ}$ ano do ensino fundamental e do terceiro ano do ensino médio, ou seja, a alunos que tinham a possibilidade de prosseguir seus estudos no campus. Para a escolha das escolas estaduais e municipais, utilizou-se o método aleatório. Assim, elas foram numeradas e, em seguida, sortearam-se quatro para serem pesquisadas. Os questionários foram aplicados da seguinte forma: 1- a 65 alunos do $3^{\circ}$ ano do Ensino Médio da E. E. "São José", localizada no Bairro Vila Bretas (divisa com o Bairro Lourdes), próximo ao Centro de Governador Valadares; 2- a 54 alunos do $9^{\circ}$ ano do Ensino Fundamental e a 58 alunos do $3^{\circ}$ ano do Ensino Médio da E. E. “Diocesano", localizada no Bairro Vila Bretas (divisa com o Bairro São Paulo); 3- a 60 alunos do $9^{\circ}$ ano do Ensino Fundamental e a 49 alunos do $3^{\circ}$ ano do Ensino Médio - Educação de Jovens e Adultos (EJA) - da E. E. "Manoel Byrro", localizada no Bairro Vera Cruz; 4- e a 65 alunos do $3^{\circ}$ ano do Ensino Médio da E. E. "Júlio Soares”, localizada no Bairro São Pedro. É importante ressaltar que as turmas também foram obtidas por meio de sorteio.

$4^{\circ}$ - Tratamento estatístico dos dados: depois de obtidas as informações, realizou-se o tratamento estatístico dos dados, que foram tabulados e organizados em formato de gráficos e quadros estatísticos. A pesquisa utilizou, assim, a abordagem quantitativa, a qual se fundamentou na quantificação dos dados obtidos por meio de questionários semiestruturados. $5^{\circ}$ - Elaboração de relatório final com apresentação e análise dos dados: de posse dos dados, os mesmos foram descritos e analisados, de forma detalhada, a fim de se oferecer um maior número de informações aos gestores do IFMG-GV.

O tratamento estatístico dos dados foi realizado "valendo-se de amostras coletadas tendo por base o objetivo de estudo, já que, em função da escala desses objetos, é impossível estudá-los integralmente. Assim, o valor das variáveis é estimado (interpolado) para as porções não amostradas com base nos valores obtidos de amostras coletadas" (MASSOM; CZAJKOWSKI, 1999). Tais variáveis, por sua vez, poderão ser visualizadas por meio de sua espacialização, que será realizada por meio de gráficos e quadros nos resultados a seguir.

\section{RESULTADOS}

\subsection{Local de origem dos atuais discentes do IFMG-GV}


O IFMG-Campus Governador Valadares possui dois cursos técnicos na modalidade de ensino integrado, o de Meio Ambiente e o de Segurança do Trabalho. Ambos tiveram entrada anual de 50 alunos por turma nos anos de 2011 e 2012. Desta forma, em 2012, foram pesquisadas quatro turmas, duas iniciantes, ou seja, no primeiro ano, e outras duas no segundo ano de cada modalidade.

No total, foram aplicados 153 questionários, a saber: 49 no primeiro ano de Meio Ambiente - MA; 54 no primeiro ano de Segurança do Trabalho - ST; 33 no segundo ano de MA e 17 no segundo ano de ST. É importante salientar que foram aplicados questionários a todos os alunos que estavam regularmente matriculados, com especial destaque para o alto índice de evasão e algumas reprovações ocorridas tanto no curso de MA como no de ST, no ano de 2011. Isto justifica os números de 54 e 17 alunos, respectivamente, no primeiro e segundo anos de ST.

Em seus dois primeiros anos de funcionamento, é possível observar que, nos cursos técnicos integrados, o campus tem atendido prioritariamente alunos que nasceram em Governador Valadares (108, dos 153) ou que residiam no município (109, dos 153) antes de ingressar no campus. Sendo assim, observa-se que $71 \%$ dos alunos dos cursos técnicos integrados já residiam no município e que apenas $16 \%$ migraram de outras cidades, que estão em um raio médio de distância de 100 km, com exceção de um(a) aluno(a) que antes residia em Palmas (TO). Os demais, 13\%, não responderam.

Além disso, $58 \%$ dos alunos residem em casas próprias, sendo que, destas, $45 \%$ já foram quitadas e as outras $13 \%$ estão em pagamento. Além disso, 30\% residem em casas alugadas e $12 \%$ em casas cedidas ou emprestadas. Estas residências localizam-se em bairros centrais e de classe média em Governador Valadares, sendo alguns próximos ao Instituto, como o Grã-Duquesa (26), Centro (12), Nossa Senhora das Graças (7), Morada do Vale (6) e Maria Eugênia (5), e outros mais distantes, como a Ilha dos Araújos (12), Lourdes (10), Vila Rica e Esplanadinha (7). Notou-se que originam poucos alunos dos bairros mais periféricos e de classe média baixa, os quais estão inseridos no Gráfico 1, na classe "outros quinze bairros" com um aluno cada. Dentre estes bairros, podem ser citados: Altinópolis, Turmalina e São Paulo. 


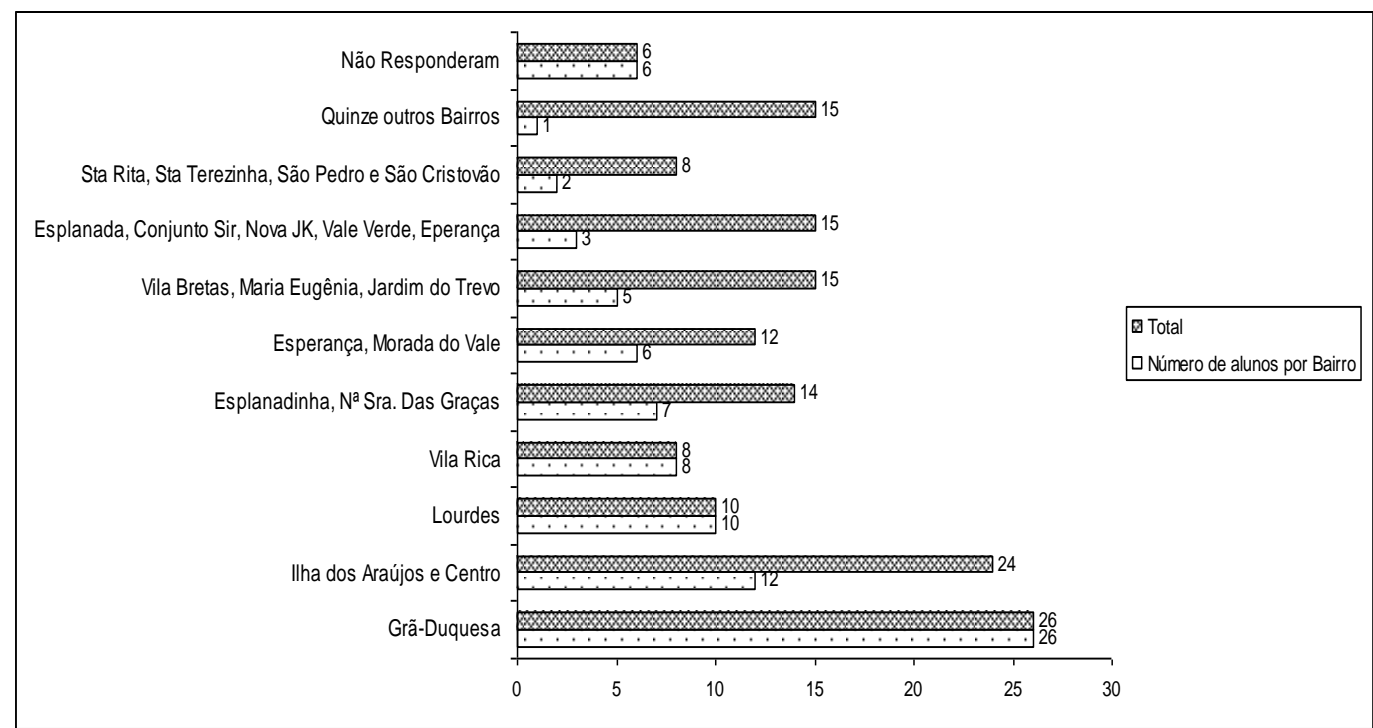

Gráfico 1 - Número de alunos dos Cursos Técnicos Integrados por bairro e valores totais em Governador Valadares

Fonte: Pesquisa realizada pelos autores

Com relação a cursos subsequentes, o IFMG-Campus Governador Valadares possui um Curso Técnico Subsequente em Segurança do Trabalho (ST), com tempo de integralização previsto para dois anos. No primeiro semestre de 2012, o curso possuía três turmas, nos seguintes períodos: $1^{\circ}, 2^{\circ}$ e $4^{\circ}$, esta última de formandos. Já no segundo semestre de 2012 , houve a entrada de uma nova turma de $1^{\circ}$ período, tendo sido aplicados, então, 51 questionários às quatro turmas anteriormente citadas, o que corresponde, segundo a coordenadora do curso, Professora Letícia Efrem, à quase totalidade de alunos frequentes. Observa-se, também, que o curso possui um índice de evasão considerável, pois, dos 40 alunos ingressantes no $1^{\circ}$ semestre de 2010 , apenas 6 continuavam no curso no $1^{\circ}$ semestre de 2012.

Assim como os cursos técnicos integrados, o subsequente em ST, em seus primeiros anos de funcionamento, tem atendido prioritariamente a alunos que nasceram em Governador Valadares (31, dos 51) ou que residiam (30, dos 51) no município antes de ingressar na instituição. Além disso, observa-se que os alunos migrantes são de municípios próximos, em torno de $100 \mathrm{~km}$.

Todavia, mesmo sendo de municípios próximos, observou-se que, atualmente, 46 alunos residem em diversos bairros de Governador Valadares, desde os mais simples, como Altinópolis e São Paulo, até os considerados de classe média, como Ilha dos Araújos e GrãDuquesa (Gráfico 2). Constatou-se, também, que 47\% dos alunos moram em residências 
próprias, e, deste percentual, apenas $8 \%$ ainda estão em pagamento. Os demais moram em residências alugadas (33\%), e emprestadas ou cedidas (18\%), sendo que alguns não responderam (2\%). Dessa forma, se antes eram apenas 30 que residiam em Governador Valadares, o curso pode ter proporcionado a migração de 16 alunos. Os demais realizam as chamadas migrações pendulares, ou seja, saem de suas residências diariamente para vir a Governador Valadares estudar.

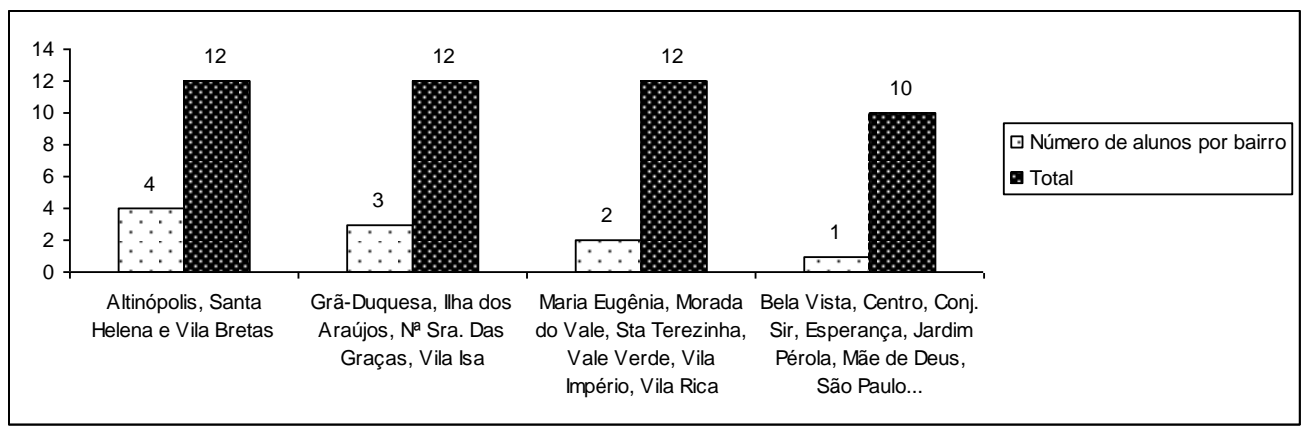

Gráfico 2 - Número de alunos do curso técnico subsequente por bairro e valores totais em Governador Valadares Fonte: Pesquisa realizada pelos autores

O Campus Governador Valadares do IFMG possui dois cursos superiores: Bacharelado em Engenharia de Produção (ENP) e Curso Superior de Tecnologia em Gestão Ambiental (TGA). No curso de Engenharia de Produção, 90 estudantes responderam os questionários. Destes, 30 estavam no $1^{\circ}$ período, 23 no $2^{\circ}$ período, 6 no $4^{\circ}$ período, 17 no $5^{\circ}$ período e 14 no $6^{\circ}$ período. Segundo a coordenadora do curso, professora Débora Nascimento, no período em que foi realizada a pesquisa ( $2^{\circ}$ semestre de 2012$)$, o curso contava um total de 153 alunos. Assim, conseguiu-se abranger cerca de $60 \%$ dos estudantes do referido curso.

Os alunos do curso são, principalmente, naturais de Governador Valadares (53 de 90) ou de municípios próximos, que distam, em média, até $100 \mathrm{~km}$. Encontraram-se, também, em menor número, os que nasceram em outros Estados, como Goiás, Rio de Janeiro e Mato Grosso, ou em outro país - EUA - o que se explica pela trajetória histórica de migração de valadarenses para o referido país. Contudo, antes de ingressar no curso, 61 alunos, dos 90 pesquisados, já residiam em Governador Valadares, o que significa que apenas 23 realizaram algum tipo de migração em decorrência do ingresso no curso, já que 6 não responderam.

Existe uma concentração maior de alunos do curso residindo nos bairros Grã-Duquesa e Centro, mais próximos do IF. Os bairros Lourdes, Ilha dos Araújos e Vila Bretas possuem menor número de alunos que os anteriores, mas que também é expressivo, levando-se em 
consideração que são bairros um pouco mais distantes. Excetuando-se o último, estes bairros são considerados, no município, de classe média - dado que pode inferir no perfil econômico dos pesquisados. Os demais discentes estão distribuídos nos mais diversos bairros do município, desde os considerados também de classe média e localizados próximos ao campus, como Morada do Vale e Cidade Nova, até os considerados de classe média baixa ou mais periférico-distantes, como o São Paulo e Jardim do Trevo (Gráfico 3).

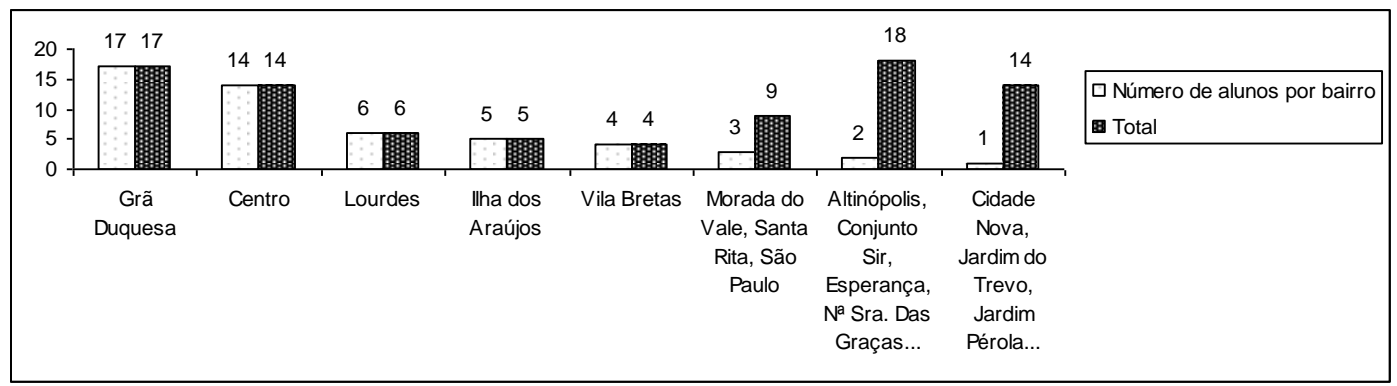

Gráfico 3 - Número de alunos do curso de ENP por bairro e valores totais em Governador Valadares Fonte: Pesquisa realizada pelos autores.

Dos 90 pesquisados, apenas 12 declararam morar com amigos ou colegas, o que caracteriza as denominadas repúblicas, e um afirmou morar sozinho. Os demais residem com seus familiares.

No curso TGA, o questionário foi aplicado aos discentes matriculados no $2^{\circ}$ semestre de 2012. Assim, entraram na pesquisa: $1^{\circ}, 2^{\circ}, 4^{\circ}$ e $5^{\circ}$ períodos do referido semestre, o que totalizou 95 discentes ou, aproximadamente, $90 \%$ dos alunos frequentes. Como nos demais cursos, também é possível observar uma evasão considerável.

Dos 95 discentes do curso, 55 nasceram em Governador Valadares e os demais nasceram, predominantemente, em municípios da região. Porém, alguns são de cidades mais distantes, como Belo Horizonte, e há ainda aqueles que nasceram em outros Estados, como São Paulo, Rio Grande do Norte e Rio de Janeiro.

Diferentemente do que foi pesquisado nos outros cursos do IFMG-GV - com exceção do curso técnico subsequente, que apresentou um valor menos expressivo - o curso de TGA foi o único em que o número de alunos que residia em Governador Valadares (47) antes de ingressar no IF foi menor que o número de nascidos no município. Ou seja, desconsiderandose o número de alunos que não responderam a questão (11), o curso pode ter promovido não apenas a migração dos nascidos em outros municípios, mas também ter propiciado o retorno de valadarenses. 
Há um maior número de alunos do curso que reside nos bairros Centro e Grã-Duquesa, que, como já explicitado anteriormente, estão mais próximos do IF. Os bairros São Paulo, Vila Bretas, Vila Isa, Santos Dumont e São Cristóvão possuem menor número de alunos que os anteriores, mas também expressivo, ao se levar em conta que são bairros um pouco mais distantes do Instituto. Estes bairros, por sua vez, são tanto de classe média alta como de classe média baixa - dado que pode inferir no perfil econômico dos pesquisados. Os demais estão distribuídos em diversos bairros do município, principalmente nos também considerados de classe média baixa e localizados em regiões mais periféricas/distantes (Gráfico 4).

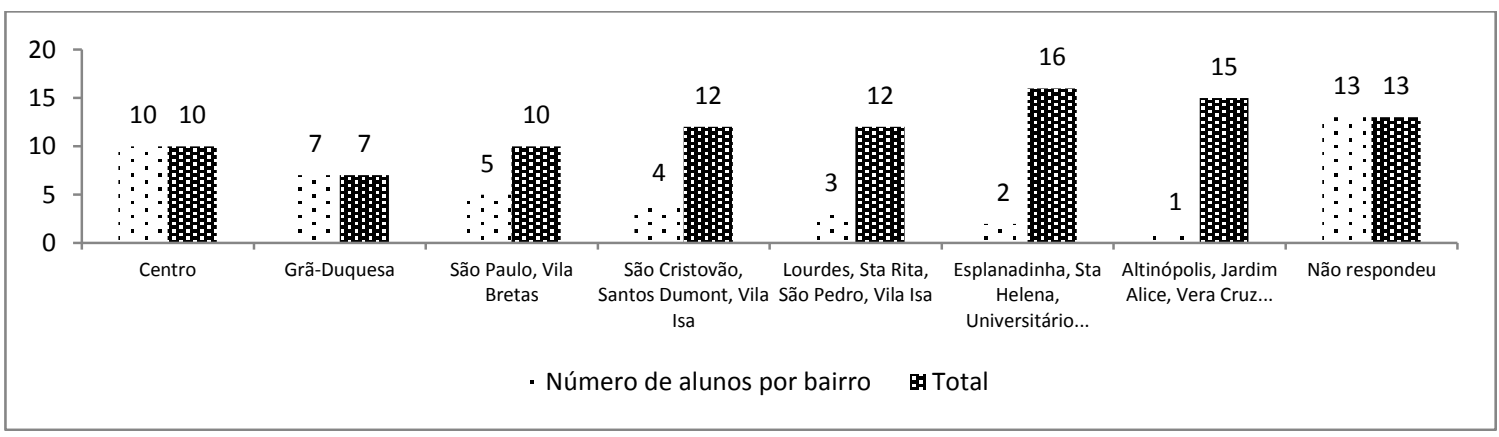

Gráfico 4 - Número de alunos do curso de TGA por bairro e valores totais em Governador Valadares Fonte: Pesquisa realizada pelos autores.

Os discentes do curso moram, em maior proporção, em residências próprias já quitadas $(34 \%)$ ou em pagamento (11\%). Existe também um percentual considerável dos que moram de aluguel (34\%) ou em residências emprestadas/cedidas (21\%).

A seguir, apresenta-se como os discentes atuais e a comunidade souberam do IFMGCampus Governador Valadares, ou seja, quais as principais ferramentas de marketing institucional foram ou não utilizadas para a divulgação do campus e de seus cursos. Demonstram-se também quais os principais cursos técnicos e superiores que a população pesquisada gostaria que fossem ofertados futuramente no campus.

\subsection{Como os discentes atuais e a comunidade ficaram sabendo do IFMG-GV e quais os cursos técnicos e superiores pretendidos}

Dos discentes do ensino técnico integrado, $73 \%$ ficaram sabendo da existência do IFMG-GV via amigos, $13 \%$ pela internet e $5 \%$ pela mãe ou parentes. Da mesma forma, a maior parte dos discentes do ensino técnico subsequente também ficou sabendo de seu curso e do IFMG via amigos (59\%) e por meio da internet (29\%). Em ambos os cursos, valores inexpressivos foram atribuídos aos meios de comunicação e propaganda, como TV, rádio e 
cartazes. Enfim, a divulgação dos cursos técnicos do Instituto se deu através da propaganda verbal, ou seja, da comunicação entre as pessoas, e não de um trabalho específico de divulgação, como as propagandas de vestibular.

Os meios de comunicação pelos quais os discentes de ENP tomaram conhecimento de seu curso/IFMG foram similares aos dos demais estudantes do campus: $42 \%$ através de amigos e $34 \%$ pela internet. Os outros $24 \%$ ficaram distribuídos entre cartazes, rádio e TV. Dos discentes do curso TGA, 50\% ficaram sabendo da existência do IFMG-GV por amigos, $38 \%$ pela internet, $5 \%$ por cartazes e $7 \%$ por outros, como familiares, TV e rádio. Notou-se, mais uma vez, que também nos cursos superiores a divulgação do Instituto não surgiu, de imediato, de um trabalho de marketing, mas principalmente da propaganda verbal, da comunicação entre as pessoas.

A maior parte dos entrevistados nas ruas centrais da cidade, $81 \%$, tem conhecimento da existência do IFMG no município e $19 \%$ nunca tinham ouvido falar. Considerando-se que praticamente todos os entrevistados residem no município, este dado se torna bem expressivo. Além disso, dos que ouviram falar, $52 \%$ foi por intermédio de amigos, $22 \%$ por internet e $26 \%$ por outros meios, como TV e rádio.

Dos 103 entrevistados no Terminal Rodoviário, 92\% já tinham ouvido falar do IFMG, ou seja, sabiam de sua instalação em Governador Valadares. É notável, mais uma vez, que tal divulgação novamente ocorreu de modo informal por meio de amigos (37\%), professores e escola $(24 \%)$ e internet (19\%). Poucos $(20 \%)$ foram os que tomaram conhecimento do campus pelos meios de divulgação tidos como veículo de propaganda, como TV e rádio.

Um número expressivo dos alunos das escolas públicas pesquisadas já tinha ouvido falar do IFMG-GV- 84\%. Destes, 44\% obtiveram a informação via amigos, $32 \%$ por TV e apenas $7 \%$ pela internet. Pela primeira vez, constatou-se a TV como meio de informação/divulgação do IFMG mais expressivo que a internet.

Dentre os cursos técnicos que a comunidade e os atuais discentes gostariam que fossem ofertados pelo campus, destacam-se, em ordem de citação: Enfermagem, Administração, Informática, Contabilidade e Edificações. É possível observar, no Quadro 1, que tais dados foram definidos prioritariamente pela opinião da comunidade pesquisada nas ruas, rodoviária e escola. Isto pode ser explicado principalmente pelo fato de os discentes do campus que já estão cursando o ensino subsequente ou superior não possuírem o anseio de realizar um curso abaixo de sua modalidade atual. 


\begin{tabular}{|c|c|c|c|c|c|c|c|c|}
\hline \multirow{2}{*}{$\begin{array}{c}\text { Cursos } \\
\text { técnicos } \\
\text { pretendidos }\end{array}$} & \multicolumn{8}{|c|}{ Local de realização da pesquisa/Público-alvo } \\
\hline & $\begin{array}{l}\text { IFMG/ } \\
\text { Integrado }\end{array}$ & $\begin{array}{c}\text { IFMG/ } \\
\text { Subsequente }\end{array}$ & $\begin{array}{c}\text { IFMG/ } \\
\text { TGA }\end{array}$ & $\begin{array}{l}\text { IFMG/ } \\
\text { ENP }\end{array}$ & Rua & Rodoviária & Escola & TOTAL \\
\hline Administração & 9 & & & & & & 52 & 61 \\
\hline Contabilidade & & & & & 35 & & 12 & 47 \\
\hline Enfermagem & 10 & & & & 34 & 18 & 27 & 89 \\
\hline Informática & 11 & & & & 10 & 4 & 35 & 60 \\
\hline Meio Ambiente & 7 & 5 & 5 & & & & & 17 \\
\hline Química & 8 & & & & & 7 & & 15 \\
\hline Edificações & 7 & & 8 & & 12 & & & 27 \\
\hline $\begin{array}{ll}\text { Segurança } \\
\text { Trabalho }\end{array}$ & & & 11 & 10 & & & & 21 \\
\hline Eletroeletrônica & & & & & 9 & 6 & & 15 \\
\hline
\end{tabular}

Quadro 1- Principais cursos técnicos pretendidos pela população pesquisada

Fonte: Pesquisa realizada pelos autores.

Sobre os cursos superiores, destacam-se, em ordem de citação: Engenharia Civil, Direito, Medicina, Administração e Engenharia Ambiental. Também com relação a este dado, a comunidade externa expressou maior interesse na oferta de cursos superiores pelo campus (Quadro 2).

\begin{tabular}{|l|c|c|c|c|c|c|c|c|}
\hline \multirow{2}{*}{\begin{tabular}{c} 
Cursos $\begin{array}{c}\text { Superiores } \\
\text { pretendidos }\end{array}$ \\
\cline { 2 - 9 }
\end{tabular}} & $\begin{array}{c}\text { IFMG/ } \\
\text { Integrado }\end{array}$ & $\begin{array}{c}\text { IFMG/ } \\
\text { Subsequente }\end{array}$ & $\begin{array}{c}\text { IFMG/ } \\
\text { TGA }\end{array}$ & $\begin{array}{c}\text { IFMG/ } \\
\text { ENP }\end{array}$ & Rua & Rodoviária & Escola & TOTAL \\
\hline Administração & & & & & 15 & 6 & 21 & 42 \\
\hline Ciências Biológicas & & & 5 & & & & 10 & 15 \\
\hline Direito & $\mathbf{6}$ & & $\mathbf{6}$ & & $\mathbf{1 8}$ & $\mathbf{8}$ & $\mathbf{3 5}$ & $\mathbf{7 3}$ \\
\hline Eng. Ambiental & & & 24 & & & 6 & & 30 \\
\hline Eng. Civil & $\mathbf{7}$ & $\mathbf{1 1}$ & & $\mathbf{2 6}$ & $\mathbf{2 5}$ & $\mathbf{1 4}$ & $\mathbf{4 4}$ & $\mathbf{1 2 7}$ \\
\hline Eng. de Produção & 7 & 9 & 6 & & & & & 22 \\
\hline Eng. Mecânica & & & & & 12 & & & 12 \\
\hline Gestão Ambiental & & 11 & & & & & & 11 \\
\hline Medicina & $\mathbf{1 4}$ & & & & $\mathbf{1 3}$ & $\mathbf{1 4}$ & $\mathbf{2 6}$ & $\mathbf{6 7}$ \\
\hline
\end{tabular}

Quadro 2 - Principais cursos superiores pretendidos pela população pesquisada Fonte: Pesquisa realizada pelos autores.

Ressalta-se, perante os dados, que há um anseio dos atuais discentes do TGA por cursar Engenharia Ambiental, fato que o torna o $5^{\circ}$ curso mais citado, e uma vontade dos atuais discentes de ENP e do curso técnico subsequente em ST em cursar Engenharia Civil, que foi o mais elencado, excetuando-se os discentes do curso técnico integrado, por todos os públicos e locais de pesquisa.

Evidencia-se ainda que, considerando os discentes dos cursos técnicos integrados como possíveis discentes de um curso superior, a manifestação de opinião sobre qual curso eles gostariam que fosse ofertado no campus foi muito baixa, pois somente 34 dos 153 
pesquisados emitiram opinião. Por fim, nota-se também que os atuais discentes do curso técnico subsequente poderão vir a ingressar em um dos cursos superiores ofertados pelo campus atualmente, tendo em vista que também foram muito citados pelos mesmos os cursos de TGA e ENP.

\section{CONCLUSÃO}

Com relação à divulgação/marketing do IFMG-GV, pode-se concluir que os discentes que ingressaram no campus até o segundo semestre de 2012 tomaram conhecimento da instituição principalmente por meio de amigos e internet. Além disso, os cursos do campus compreendem prioritariamente moradores de Governador Valadares, localizados em bairros de classe média, e, em menor número, os naturais de municípios próximos. Ainda em relação à divulgação, os dados obtidos nas ruas e na rodoviária não estão muito diferentes, observando-se um pouco de exceção para as escolas, onde a TV foi a mais citada. Enfim, o IFMG-GV, via Comissão Local do Processo Seletivo, precisa investir mais em meios de divulgação populares, como visitas às escolas do município e da região, TV, rádio e cartazes, a fim de que o campus se torne mais conhecido em Governador Valadares e região.

Esta falta de divulgação dos Institutos Federais e, consequentemente, do IFMG-GV e seus cursos, bem como a falta de informação sobre os catálogos de cursos técnicos do MEC foram observadas na dificuldade dos pesquisados em opinar sobre quais cursos desta modalidade gostariam que fossem ofertados pelo campus.

É notável que muitos dos cursos técnicos e superiores citados já são ofertados no município e na região, principalmente por instituições de ensino particulares e, mais recentemente, pela UFJF. Dessa forma, cabe aos gestores avaliar quais cursos realmente devem ser ofertados, além de analisar, em conjunto com as coordenações de curso, especialmente a do ensino integrado, o porquê de poucos dos atuais discentes do campus terem sugerido/mostrado interesse pela realização dos atuais cursos ou pela oferta de algum novo curso superior pela instituição.

Por fim, espera-se que os resultados da pesquisa sejam analisados e utilizados como uma ferramenta norteadora da política de expansão do Campus Governador Valadares, com o objetivo de realizar um melhor atendimento às necessidades e aspirações das comunidades locais e regionais. Esta ação vai ao encontro da atual política educacional do Governo Federal, que objetiva, dentre outras metas, a expansão do ensino técnico e tecnológico no País 
e, consequentemente, a capacitação profissional dos cidadãos. Sugere-se também que a pesquisa seja realizada de forma contínua, sempre procurando abranger uma população maior a fim de se verificar a manutenção ou alteração dos dados.

\section{REFERÊNCIAS}

CRESPO, A. A. Estatística fácil. 19. Ed. São Paulo: Saraiva, 2009.

INSTITUTO BRASILEIRO DE GEOGRAFIA E ESTATÍSTICA (IBGE). Censo demográfico 2010. 2010. Disponível em: <http://www.ibge.gov.br/cidadesat/index.php>. Acesso em: 05 ago. 2013.

INSTITUTO FEDERAL DE MINAS GERAIS (IFMG). Projeto pedagógico do curso de Tecnologia em Gestão Ambiental. Coordenação do Curso de Tecnologia Ambiental. IFMG: Governador Valadares, 2012.

KOTLER, P.; KELlER, K. L. Administração de marketing. 12. ed. São Paulo: Pearson Prentice Hall, 2006.

MARCONI, M. de A.; LAKATOS, E. M. Fundamentos de metodologia científica. 5. ed. São Paulo: Atlas, 2003.

MASSON, R.; CZAJKOWSKI. Métodos de interpolação para modelagem de superfícies. Rio Claro: Unesp, 1999.

MAXIMIANO, A. C. A. Introdução à administração. 7. ed. São Paulo: Atlas, 2010.

OLIVEIRA, M. M. de. Como fazer: projetos, relatórios, monografias, dissertações e teses. 3. ed. Rio de Janeiro: Elsevier, 2005.

OTRANTO, C. R. A Reforma da educação superior do governo Lula: da inspiração à implantação. Disponível em: <http://www.anped.org.br/reunioes/29ra/trabalhos/ trabalho/GT11-1791--Int.pdf>. Acesso em: 08 fev. 2012.

PAULA, M. F. de. Reforma da Educação Superior do Governo Lula: as políticas de democratização do acesso em foco. Revista Argentina de Educación Superior. n. 1, p. 152$172,2009$.

Recebido em: 02/09/2013

Aprovado em: 04/11/2013 